\title{
The Credit Risk Assessment Model of Internet Supply Chain Finance: Multi-Criteria Decision-Making Model with the Principle of Variable Weight
}

\author{
Yueliang Su, Baoyu Zhong \\ School of Business, South China University of Technology, Guangzhou, China \\ Email: 490943753@qq.com
}

How to cite this paper: Su, Y.L. and Zhong, B.Y. (2016) The Credit Risk Assessment Model of Internet Supply Chain Finance: Multi-Criteria Decision-Making Model with the Principle of Variable Weight. Journal of Computer and Communications, 4, 1-11.

http://dx.doi.org/10.4236/jcc.2016.416001

Received: November 10, 2016

Accepted: December 4, 2016

Published: December 9, 2016

Copyright $\odot 2016$ by authors and Scientific Research Publishing Inc. This work is licensed under the Creative Commons Attribution International License (CC BY 4.0). http://creativecommons.org/licenses/by/4.0/

\begin{abstract}
The characteristics of the financing model are firstly analyzed when the e-commerce enterprises participate in the supply chain finance. Internet supply chain finance models are divided into three categories with the standard of whether the Electronic commerce enterprises provide funds for small and medium enterprises instead of banks. And then we further study the financing process and the functions of the e-commerce platform with specific examples. Finally, combined with the characteristics of the supply chain finance model, we set up a small and medium enterprises credit evaluation model based on the principle of variable weight with its dynamic data. At the same time, a multi time points and multi indicators decision-making method based on the principle of variable weight is proposed and a specific example is presented. In this paper, the Multi-criteria decision-making model with the principle of variable weight has been used two times. At last, a typical case has been analyzed based on this model with a higher accuracy rate of credit risk assessment.
\end{abstract}

\section{Keywords}

Credit Risk Assessment Model, Multi-Criteria Decision-Making Model, Variable Principle

\section{Introduction}

"Internet plus", as a new model of the development of the Internet, is a new form of the social development. "Internet plus" means that Internet and traditional industry mix together deep and a new form of development is created using Internet information 
technology and the Internet platform, etc. [1]. On the background of the Internet, based on the e-commerce platform, supply chain finance also has a new development form. On December 10th 2013, a Jingdong's Internet financial product, "Jing BaoBei”, sets off a wave of supply chain finance again [2] [3]. Bei Jing Bao is a financing model based on the purchasing, sales, finance and other data of suppliers without a guarantee or collateral. Jingdong analyses and determines a supplier's loan capacity and credit risk according to the supplier's registration information, purchasing data, sales data and network behavior data, etc. [4]. On the one hand, the Internet has brought more possibilities for the development of supply chain finance. On the other hand, the accuracy of credit risk assessment of small and medium sized enterprises is also more and more important. Based on this, this paper analyses the change of the financing mode of the supply chain finance based on the e-commerce platform on the background of the Internet. At the same time, standing in the perspective of the e-commerce platform, how to use dynamic network data to evaluate the credit risk of small and medium financing customers is proposed.

\section{Internet Supply Chain Finance Mode}

\subsection{The First Supply Chain Finance Financing Mode Based on E-Commerce Platform}

In the first mode of supply chain finance, the e-commerce platform not only provides trading platform, but also directly participates in the supply chain as the core enterprise of the supply chain. At the same time, e-commerce platform corporates with the bank, providing guarantee credit for the small and medium enterprise of capital shortage [5].

The biggest difference between traditional and Internet supply chain finance is that the transaction and financing process of all enterprises in the whole supply chain are completed on line. The typical e-commerce platform of this model is the Jingdong Mall. First of all, the electronic commerce enterprise orders products from upstream supplier who will provide products according to the orders. Next, as the core enterprise with a more powerful position, such as Jingdong Mall, the e-commerce platform does not take direct payment but opens acceptance bill to the upstream supplier and promises to pay after a certain period. Then, the e-commerce platform sales the products online. Due to the shortage of funds, upstream supplier has to apply to the bank for financing loans, pledging order and acceptance bills from the electronic commerce enterprise. After verifying the relevant order information, the e-commerce platform makes guarantees to the bank so that bank loans to upstream the supplier. After the entire sales season, the supplier repays the loan after receiving order receivables from the electronic commerce enterprise. Figure 1 shows the process of the first supply chain finance financing mode.

Compared to the traditional supply chain finance, banks will no longer only assess the financial condition and collateral of the financing enterprise, but also all data on the e-commerce platform. On the basis of more data, the bank can analyze the financial condition of financing enterprises, procurement, sales, etc. Considering the performance of the whole supply chain, including the comprehensive ability of upstream and 


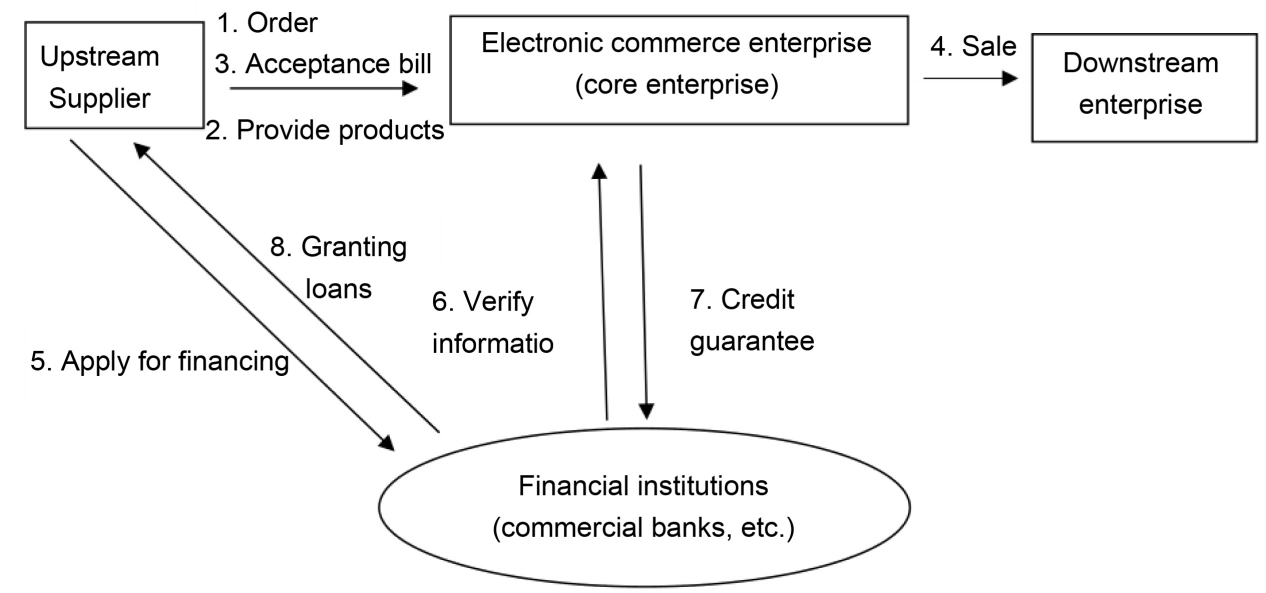

Figure 1. The first supply chain finance financing mode.

downstream companies, supply chain operations, etc., banks can accurately and effectively determine the loan capacity and credit risk of financing enterprises, which effectively reduce the risk of bank loans [6].

\subsection{The Second Supply Chain Finance Financing Mode Based on E-Commerce Platform}

In the second mode of supply chain finance, the e-commerce platform does not directly participate in the supply chain, but provides a trading platform to the upstream suppliers and downstream retailers or customers. However, the e-commerce platform still grasp most of the information in the supply chain. Because of that, the e-commerce platform can provide financing services for small and medium sized enterprises by establishing a loan company or applying for a banking licence [7].

The electronic commerce enterprise provides a trading platform for the trading enterprises instead of directly participating in the supply chain. First of all, downstream enterprise orders products from the upstream supplier. Then the supplier provides products for the downstream enterprise according to order. And then the downstream enterprise opens an acceptance bill, promising the supplier to pay after a certain period of time, which becomes accounts receivable. In this process, e-commerce enterprise does not participate in the transaction, but it can get the trading behavior information and logistics information, etc. of the two sides of the transaction. After the comprehensive consideration of the financial situation of the financing enterprise and online transaction data, the electronic commerce enterprise assesses the credit risk level of the financing enterprise in the supply chain. The electronic commerce enterprise controls the risk by accurately assessing the ability and the willingness of the enterprise to repay. After that, the electronic commerce enterprise provides different rates of financing products for the financing enterprises according to the credit risk level. Enterprises with a lower level of credit risk can be offered unsecured financing services with a lower interest rate. On the other hands, the electronic commerce enterprise may offer financing services with some collateral for the enterprise whose credit risk level is high. When 
facing the financing difficulties, the enterprise can apply for financing application to the electronic commerce enterprise that can quickly provide the corresponding services. Figure 2 shows the process of the second supply chain finance financing mode.

In the second mode of supply chain finance, there is no bank, which is different from the first mode of supply chain finance. The electronic commerce enterprise replaces the bank to provide the small and medium-sized enterprises with the financing service. The electronic commerce enterprise establishes a rich database and credit records of the enterprises on the e-commerce platform and provides financing services for customers with financing difficulties on the platform. In this kind of mode of supply chain, it is very important for electronic commerce enterprises to assess the credit risk level of the financing enterprises.

\subsection{The Third Supply Chain Finance Financing Mode Based on E-Commerce Platform}

In this section, we analyze the third supply chain finance financing mode that is the combination of the two modes of supply chain finance analyzed above. But it is different from the two. In the third supply chain finance financing mode, the electronic commerce enterprise is the core enterprise in the supply chain, who orders products from the upstream supplier and sales to the downstream enterprises. Besides, as a financial institution with a strong capital, the electronic commerce enterprise loans to the enterprises with a shortage of capital in the supply chain and earn the interest [8]. Figure 3 shows the process of the third supply chain finance financing mode.

\section{The Model}

The credit risk of small and medium-sized financing enterprises is relatively high due to shortage of its own funds and weak comprehensive ability. So the credit risk assessment is particularly important. In the Section 2, we analyzed the three kinds of Internet supply chain finance mode based on the Internet. In this section, from the perspective

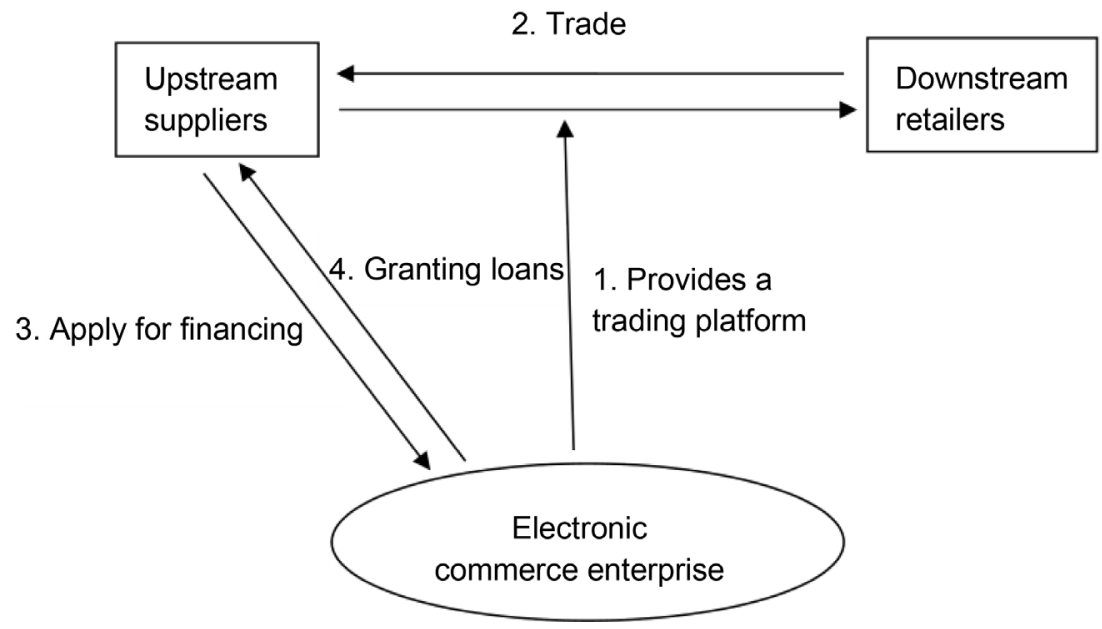

Figure 2. The second supply chain finance financing mode. 


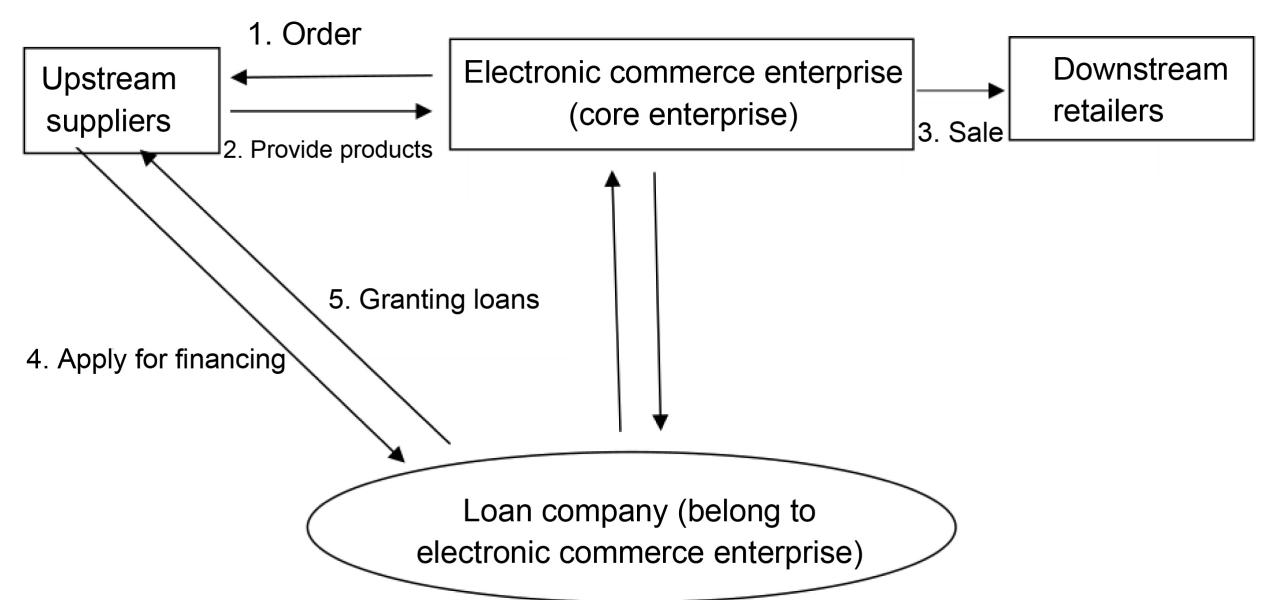

Figure 3. The third supply chain finance financing mode.

of electronic business enterprise, we build the credit risk assessment indicators combined with the characteristics of Internet supply chain financing mode and its platform data. When evaluating the credit risk of the financing enterprises in the supply chain, multi indicator decision problem arises. At the same time, due to the real-time nature of Internet data, the indicator state value will change with time. Based on this, this paper establishes a Multi-criteria decision-making model based on variable weight [9] [10].

\subsection{A Variable Weight Model with Multiple Time Points of Any Indicator}

In the selection of the impact indicator of small and medium enterprises in supply chain financing credit evaluation, there are some indicator state values changing over time and the information value decaying. In order to determine the comprehensive function of the indicator in different time, we consider using the variable weight theory. Next, excited variable state vectors is introduced [11].

Given mapping $S:[0,1]^{m} \rightarrow[0,1]^{m}$ such that $X \rightarrow S(X)=\left(S_{1}(X), S_{2}(X), \cdots, S_{m}(X)\right)$, where $S_{i}(X)=[0,1]^{m} \rightarrow[0,1]$.

$S(X)=\left(S_{1}(X), S_{2}(X), \cdots, S_{m}(X)\right)$ is called excited variable state vectors if $S$ satisfies the following axioms

1) $S_{i}(X) \geq S_{j}(X)$ when $x_{i} \geq x_{j}$,

2) $S_{i}(X)=S_{i}\left(x_{1}, x_{2}, \cdots, x_{m}\right)$ is continuous on each $x_{i}$

3) For any constant weight vector, $w_{0}=\left(w_{1}, w_{2}, \cdots, w_{m}\right)$, there is a variable state vector

$$
w(X)=\frac{w_{0} * S(X)}{\sum_{i=1}^{m} w_{i} S_{i}(X)}
$$

Assuming that there are $N$ indicators, $f=\left(f_{1}, f_{2}, \cdots, f_{N}\right)$, whose values changing over time. The values of $M$ indicators $f_{i}$ in $M$ time points are $y_{i}=\left(y_{i 1}, y_{i 2}, \cdots, y_{i M}\right)$, where $y_{i M}$ is the closest state value from the current time. Given the constant 
weight vector $w_{0}=\left(w_{1}, w_{2}, \cdots, w_{M}\right)$, the variable state vector

$S_{i}\left(y_{i}\right)=\left(S_{i 1}\left(y_{i}\right), S_{i 2}\left(y_{i}\right), \cdots, S_{i M}\left(y_{i}\right)\right)$ can be defined as

$$
S_{i j}\left(y_{i 1}, y_{i 2}, \cdots, y_{i M}\right)=\frac{y_{i j}}{M-j+1} j=1,2, \cdots, M
$$

It can be proved that the variable state vectors $S_{i j}\left(y_{i 1}, y_{i 2}, \cdots, y_{i M}\right)$ satisfies the defined conditions of excited variable state vectors. So the value of all variable state vectors in different time points $w_{i}$ can be defined

$$
w_{i}\left(y_{i}\right)=\frac{w_{0} * S_{i}\left(y_{i}\right)}{\sum_{j=1}^{M} w_{j} S_{i j}\left(y_{i}\right)}=\frac{\left(w_{1} S_{1}\left(y_{i}\right), w_{2} S_{2}\left(y_{i}\right), \cdots, w_{M} S_{M}\left(y_{i}\right)\right)}{\sum_{j=1}^{M} w_{j} S_{i j}\left(y_{i}\right)}
$$

Calculate the values of the comprehensive function of all indicatores in different time points which are the Hadamard product of variable vectors and state values,

$$
y_{j}^{\prime}=w_{i}\left(y_{i}\right) \circ y_{i}
$$

Finally, the state values of all evaluation indicators can be defined as

$$
x_{i}= \begin{cases}y_{i} y_{i} & \text { changes by time } \\ y_{i}^{\prime} y_{i} & \text { doesn't change by time }\end{cases}
$$

\subsection{A Variable Weight Model with Multiple Indicators}

The state value of indicator is different, as well as the importance of different indicator. In traditional, constant weight variable is usually used to determine the importance of indicator. In this paper, the weight of indicator is also adopted to the variable weight theory in order to study the influence of the state value on the indicator. Satisfaction Principle is introduced [12].

For a multi criteria decision making problem, assuming a decision set $U$, an indicator set related decision making problem $f=\left(f_{1}, f_{2}, \cdots, f_{m}\right)$ and a constant weight vector of the indicators, $w=\left(w_{1}, w_{2}, \cdots, w_{m}\right)$. The value of the indicator $f$ is $X=\left(x_{1}, x_{2}, \cdots, x_{m}\right)$ and $m_{0}$ is the number of satisfaction. For any choice $u \in U$, the choice $u$ is the satisfaction choice if there are more than $m_{0}$ indicators who are satisfactory. Indicator $x_{i}$ is satisfactory if $x_{i}>a_{i}$ where $a_{i}$ is the basic number whose values is the standard given by decision makers. Assuming that there are $\mathrm{m}$ small and medium sized enterprises $p=\left(p_{1}, p_{2}, \cdots, p_{m}\right)$ and $N$ indicators that measure the credit risk of small and medium sized enterprises. For any $p_{t}$ in $p=\left(p_{1}, p_{2}, \cdots, p_{m}\right)$, assuming that the value of $\mathrm{N}$ indicators is $x_{t}=\left(x_{t 1}, x_{t 2}, \cdots, x_{t N}\right)$ and the number of satisfaction is $m_{0}$. In order to determine the constant weight vector more objectively, this paper uses the analytic hierarchy process to determine the value of the constant weight vector $w_{0}^{\prime}=\left(w_{1}^{\prime}, w_{2}^{\prime}, \cdots, w_{N}^{\prime}\right)$. The state value of all indicators are standardized by Z-score method and then the basic number can be $a=(0,0, \cdots, 0)$. According to Liu Chang (2014, [13]), variable state vector $S_{t}\left(x_{t}\right)=\left(S_{t 1}\left(x_{t}\right), S_{t 2}\left(x_{t}\right), \cdots, S_{t N}\left(x_{t}\right)\right)$ can be defined as

$$
S_{t j}\left(x_{t 1}, x_{t 2}, \cdots, x_{t N}\right)= \begin{cases}\mathrm{e}^{\theta x_{t j}} & x_{t j} \geq 0 \\ 1 & x_{t j}<0\end{cases}
$$


where $\theta$ is the excited factor, $\theta=\frac{\eta}{\xi}, \quad \eta=\mu\left(\xi-m_{0}\right), \mu(t)=\left\{\begin{array}{ll}t+1 & t \geq 0 \\ 0 & t<0\end{array}, \quad \xi\right.$ is the number of satisfaction indicators that the number of satisfied condition $x_{t j} \geq 0$ and $\xi=\sum_{j=1}^{N} v\left(x_{t j}\right), \quad v(t)= \begin{cases}1 & t \geq 0 \\ 0 & t<0\end{cases}$

It can be proved easily that $S_{t j}\left(x_{t 1}, x_{t 2}, \cdots, x_{t N}\right)$ satisfies all conditions of the definition excited variable state vectors and then the value of the variable weight vector of all suppliers $w_{t}$ can be calculated

$$
w_{t}\left(x_{t}\right)=\frac{w_{0}^{\prime} * S_{t}\left(x_{t}\right)}{\sum_{j=1}^{N} w_{j}^{\prime} S_{t j}\left(x_{t}\right)} \frac{\left(w_{1}^{\prime} S_{1}\left(x_{t}\right), w_{2}^{\prime} S_{2}\left(x_{t}\right), \cdots, w_{N}^{\prime} S_{N}^{\prime}\left(x_{t}\right)\right)}{\sum_{j=1}^{N} w_{j}^{\prime} S_{t j}\left(x_{t}\right)}
$$

Finally, calculate the values of the comprehensive function of all small and medium sized enterprises in different indicators which are the Hadamard product of variable vectors and state values,

$$
x_{t}^{\prime}=w_{t}^{\prime}\left(x_{t}\right) \circ x_{t}
$$

Equation (8) gives the final scores of all small and medium sized enterprises.

\section{Case Analysis}

\subsection{Index Design and Data Description}

Based on the characteristics of the supply chain on the electronic platform and the literature of supply chain, the credit risk assessment index is constructed as Table 1 .

According to the credit risk assessment indexes, this paper collects the data through the questionnaire to the merchant and the electronic business platform. Qualitative indexes take 5 points system score, and quantitative indexes are from the electronic business platform history records. There were 13 valid questionnaires returned. Therefore,

\begin{tabular}{|c|c|c|}
\hline First-grade index & Second-grade index & Index description \\
\hline \multirow{2}{*}{$\begin{array}{l}\text { Credit status of the } \\
\text { financing } \\
\text { enterprise } \\
\text { B1 }\end{array}$} & $\begin{array}{l}\text { Registration information } \\
\qquad \mathrm{X} 1\end{array}$ & $\begin{array}{l}\text { The basic information of a financing enterprise when } \\
\text { it is registered on the platform }\end{array}$ \\
\hline & $\begin{array}{c}\text { Financial disclosure } \\
\text { quality X2 }\end{array}$ & Financial statement audit and information disclosure \\
\hline \multirow{4}{*}{$\begin{array}{c}\text { Financing project } \\
\text { status } \\
\text { B2 }\end{array}$} & Sales profit margin $\mathrm{X} 3$ & Sales profit/sales revenue \\
\hline & Purchasing data X4 & Project related purchasing data \\
\hline & Sales data X5 & Project related sales data \\
\hline & $\begin{array}{c}\text { Returned merchandise } \\
\text { data X6 }\end{array}$ & Whether there is a record of returned merchandise \\
\hline \multirow{2}{*}{$\begin{array}{l}\text { Operation status } \\
\text { online B3 }\end{array}$} & Online operation level X7 & $\begin{array}{l}\text { The age of online operation of the } \\
\text { financing enterprise, etc. }\end{array}$ \\
\hline & Informatization level X8 & Online business conditions \\
\hline
\end{tabular}

Table 1. The credit risk evaluation index of internet supply Chain Finance. 
a Multi-criteria decision-making model can be constructed with 13 financing enterprises $p=\left(p_{1}, p_{2}, \cdots, p_{13}\right)$ and 8 credit risk assessment indexes $f=\left(f_{1}, f_{2}, \cdots, f_{8}\right)$. Some indexes have three months of data $y_{i}=\left(y_{i 1}, y_{i 2}, y_{i 3}\right)$.

\subsection{A Variable Weight Model with Multiple Time Points of Any Indicator}

In the collected data, some of them change with time. Sales profit margin X3, Purchasing data X4, Sales data X5 and Returned merchandise data X6 need to be calculated the values of the comprehensive function with three months record. Given a constant weight vector $w_{0}=\left(w_{1}, w_{2}, w_{3}\right)=(0.2,0.3,0.5)$, the comprehensive function value of any indicator in three months can be calculated by Equation (5).

Besides, this paper uses the analytic hierarchy process to determine the value of the constant weight vector $\mathrm{w}_{0}^{\prime}$. According to the relative importance of each index, the judgment matrix of the hierarchical structure is determined. The relative importance between each other of the First-grade index can be expressed as a matrix $A$ and the Second-grade index one can be expressed as a matrix $B, C, D$

$$
A=\left(\begin{array}{lll}
1 & 3 & 5 \\
& 1 & 5 \\
& & 1
\end{array}\right) \quad B=\left(\begin{array}{lll}
1 & 1 & 3 \\
& 1 & 3 \\
& & 1
\end{array}\right) \quad C=\left(\begin{array}{ccc}
1 & 0.2 & 3 \\
& 1 & 5 \\
& & 1
\end{array}\right) \quad D=\left(\begin{array}{ll}
1 & 3 \\
& 1
\end{array}\right)
$$

The relative weight and combined weight of index can be determined by MATLAB according the judgment matrix. The relative weight and combination weight are shown as Table 2 .

\subsection{A Variable Weight Model with Multiple Indicators}

According to variable weight theory, when an index meets the requirements of financial institutions, increase the weight of the index to indicate the impact of the index, or to reduce its weight. Constant weight vector $w_{0}^{\prime}=\left(w_{1}, w_{2}, w_{3}, w_{4}, w_{5}, w_{6}, w_{7}, w_{8}\right)=(0.25,0.25,0.107,0.064,0.208,0.031,0.067,0.022)$, can be obtained from Table 2 by analytic hierarchy process. By Equation (6), the variable

Table 2. The relative weight and combination weight of index by AHP.

\begin{tabular}{ccccc}
\hline & B1 (0.067) & B2 (0.303) & B3 (0.090) & Combined weight \\
\hline X1 & 0.412 & 0.000 & 0.000 & 0.250 \\
X2 & 0.412 & 0.000 & 0.000 & 0.250 \\
X3 & 0.176 & 0.000 & 0.000 & 0.107 \\
X4 & 0.000 & 0.211 & 0.000 & 0.064 \\
X5 & 0.000 & 0.686 & 0.000 & 0.208 \\
X6 & 0.000 & 0.102 & 0.000 & 0.031 \\
X7 & 0.000 & 0.000 & 0.750 & 0.067 \\
X8 & 0.000 & 0.000 & 0.250 & 0.022
\end{tabular}


weight vectors of each index of the 13 financing enterprises can be obtained. Variable weight vector of each index of sample financing enterprise are shown as Table 3.

By Equation (8), the final scores of 13 small and medium sized enterprises are calculated. Take $\mathrm{P}$ as a boundary value. When $\mathrm{P}$ is larger, the credit risk degree of the financing enterprise is lower; when $\mathrm{P}$ is smaller, the credit risk of the financing enterprise is higher. The values are given as Table 4.

The final score values and risk assessment degrees of the 13 financing enterprises based on Multi-criteria decision-making (MID) model with the principle of variable weight and Analytic hierarchy process (AHP) model are shown as Table 5.

\section{Conclusion}

The credit risk of small and medium-sized financing enterprises is relatively high due to shortage of its own funds and weak comprehensive ability. In traditional supply chain finance, when evaluating the credit level of small and medium sized enterprises, banks often take the analysis of the financial data of small and medium-sized enterprises, and so on. In this paper, from the perspective of electronic business enterprise, we build the credit risk assessment indicators combined with the characteristics of Internet supply chain financing mode and its platform data. In this paper, the credit risk assessment index is constructed through analysis of the characteristics of the financing model and the change of the model when the Electronic commerce enterprise participating in the

Table 3. Variable weight vector of each index of sample financing enterprise.

\begin{tabular}{ccccccccc}
\hline Sample & $w_{1}\left(x_{t}\right)$ & $w_{2}\left(x_{t}\right)$ & $w_{3}\left(x_{t}\right)$ & $w_{4}\left(x_{t}\right)$ & $w_{5}\left(x_{t}\right)$ & $w_{6}\left(x_{t}\right)$ & $w_{7}\left(x_{t}\right)$ & $w_{8}\left(x_{t}\right)$ \\
\hline P1 & 0.190 & 0.225 & 0.154 & 0.089 & 0.206 & 0.011 & 0.121 & 0.005 \\
P2 & 0.250 & 0.250 & 0.107 & 0.064 & 0.208 & 0.031 & 0.067 & 0.022 \\
P3 & 0.250 & 0.250 & 0.107 & 0.064 & 0.208 & 0.031 & 0.067 & 0.022 \\
P4 & 0.252 & 0.298 & 0.087 & 0.028 & 0.273 & 0.014 & 0.040 & 0.007 \\
P5 & 0.146 & 0.245 & 0.233 & 0.084 & 0.158 & 0.018 & 0.095 & 0.021 \\
P6 & 0.188 & 0.315 & 0.098 & 0.048 & 0.204 & 0.055 & 0.064 & 0.027 \\
P7 & 0.250 & 0.250 & 0.107 & 0.064 & 0.208 & 0.031 & 0.067 & 0.022 \\
P8 & 0.250 & 0.250 & 0.107 & 0.064 & 0.208 & 0.031 & 0.067 & 0.022 \\
P9 & 0.179 & 0.305 & 0.085 & 0.106 & 0.195 & 0.022 & 0.091 & 0.016 \\
P10 & 0.250 & 0.250 & 0.107 & 0.064 & 0.208 & 0.031 & 0.067 & 0.022 \\
P11 & 0.565 & 0.170 & 0.043 & 0.059 & 0.109 & 0.012 & 0.027 & 0.015 \\
P12 & 0.163 & 0.270 & 0.151 & 0.092 & 0.175 & 0.047 & 0.080 & 0.023 \\
P13 & 0.250 & 0.250 & 0.107 & 0.064 & 0.208 & 0.031 & 0.067 & 0.022 \\
\hline
\end{tabular}

Table 4. The final score boundary value and risk degree.

\begin{tabular}{cccccc}
\hline$P$ & $P \geq 1$ & $0 \leq P \leq 1$ & $-1 \leq P \leq 0$ & $-2 \leq P \leq-1$ & $P \leq-2$ \\
\hline risk degree & 1 & 2 & 3 & 4 & 5 \\
\hline
\end{tabular}


Table 5. The final score values and risk assessment degrees of the 13 financing enterprises.

\begin{tabular}{lccccc}
\hline The score & $\begin{array}{c}\text { Risk degree } \\
\text { prediction } \\
\text { based on MID }\end{array}$ & $\begin{array}{c}\text { The score } \\
\text { based on AHP }\end{array}$ & $\begin{array}{c}\text { Risk degree } \\
\text { prediction } \\
\text { based on AHP }\end{array}$ & Risk degree \\
\hline P1 & 1.769 & 1 & 1.630 & 1 & 1 \\
P2 & -0.549 & 3 & -0.721 & 3 & 3 \\
P3 & -1.557 & 4 & -1.352 & 4 & 4 \\
P4 & 1.392 & 1 & 1.384 & 1 & 2 \\
P5 & 0.523 & 2 & 0.214 & 2 & 3 \\
P6 & 0.256 & 2 & 0.022 & 2 & 3 \\
P7 & -0.615 & 3 & -0.762 & 3 & 3 \\
P8 & -0.290 & 3 & 0.027 & 2 & 2 \\
P9 & 0.043 & 2 & -0.004 & 3 & 3 \\
P10 & -0.489 & 3 & -0.679 & 3 & 2 \\
P11 & 0.613 & 2 & 0.480 & 2 & 2 \\
P12 & 0.454 & 2 & 0.181 & 2 & 3 \\
P13 & -0.238 & 3 & -0.420 & 3 & 2 \\
\hline
\end{tabular}

supply chain finance. At the same time, the index state value will change with time due to the real-time nature of Internet data. Then a multi-criteria decision-making model based on the principle of variable weight was established combined with the characteristics of Internet supply chain financing model, complexity and dynamic of data and the credit risk assessment index. Finally, based on the case validation, through comparing with the results of the traditional analytic hierarchy process, it is proved that the Multi-criteria decision-making model have higher accuracy rate of credit risk assessment for financing enterprises.

\section{Acknowledgements}

This research was supported by "the Fundamental Research Funds for the Central Universities” (2015ZKYJZX02) and Guangzhou Financial Services Innovation and Risk Management Research Base.

\section{References}

[1] Editorial Department of China Construction Information (2015) To Meet the "Internet plus” Era. China Construction Information, 6, 8-9.

[2] Editorial Department of Era of Financial Science and Technology (2014) Ricoh (China) Color Management Expert Awarded “G7" Experts Certification. Financial Technology Time, 1, 8.

[3] Min, W.W. and Luo, L. (2015) Innovation Is the Only Way Out-An Interview with Yao Naisheng, Vice President of Jingdong Finance. Modern Bankers, 3, 90-93.

[4] Editorial Department of Era of Financial Science and Technology (2014) China's First Mo- 
bile Payment Block. Financial Technology Time, 1, 8.

[5] Wang, C. (2007) Research on Financing Model of Small and Medium Sized Enterprises Based on Supply Chain Finance. Tianjin University of Finance Economics, Tianjin.

[6] Pang, J. (2011) An Analysis of the Financing Mode of Pre Payment Based on the Supply Chain Finance. Beijing Jiaotong University, Beijing.

[7] Sun, R.Y. (2012) Mobile Phone OEM J Supplier Management Strategy. Tianjin University, Tianjin.

[8] Tang, S.D. (2014) Analysis on the Present Situation and Development Trend of Supply Chain Finance in Commercial Banks. Rural Finance Research, 5, 5-7.

[9] Amid, A., Ghodsypour, S. and Obrien, C. (2006) Fuzzy Multi Objective Linear Model for Supplier Selection in a Supply Chain. International Journal of Production Economics, 104, 394-407.

[10] Amid, A., Ghodsypour, S. and O’Brien, C. (2011) A Weighted Max-Min Model for Fuzzy Multi-Objective Supplier Selection in a Supply Chain. International Journal of Production Economics, 131, 139-145.

[11] Wang, Y. (2005) Research on Supplier Selection Method Based on Variable Weight Theory. University of Electronic Science and Technology, Chengdu.

[12] De, Q., Li, C.H.M. and Li, H.X. (2003) A Multifactor Decision Making Method Based on Satisfaction Principle. Systems Engineering Theory and Practice, 23,104-109.

[13] Liu, C., Yacine, O., Antoine, N., Abdelaziz, B. and Zhou, J.L. (2014) Multi-Criteria Decision Making Based on Trust and Reputation in Supply Chain. International Journal of Production Economics, 147, 362-372. for you:

Accepting pre-submission inquiries through Email, Facebook, LinkedIn, Twitter, etc. A wide selection of journals (inclusive of 9 subjects, more than 200 journals)

Providing 24-hour high-quality service

User-friendly online submission system

Fair and swift peer-review system

Efficient typesetting and proofreading procedure

Display of the result of downloads and visits, as well as the number of cited articles

Maximum dissemination of your research work

Submit your manuscript at: http://papersubmission.scirp.org/

Or contact jcc@scirp.org 